LUZ, JMQ; BITTAR, CA; OLIVEIRA RC; NASCIMENTO, AR; NOGUEIRA, APO. 2016. Desempenho e divergência genética de genótipos de tomate para processamento industrial. Horticultura Brasileira 34: 483-490. DOI - http://dx.doi.org/10.1590/S0102-053620160406

\title{
Desempenho e divergência genética de genótipos de tomate para processamento industrial
}

\author{
José MQ Luz ${ }^{1}$; Cecilia A Bittar ${ }^{1}$; Roberta C Oliveira ${ }^{1}$; Abadia R Nascimento²; Ana PO Nogueira ${ }^{1}$ \\ ${ }^{1}$ Universidade Federal de Uberlandia (UFU), Uberlândia-MG, Brasil; jmagno@ufu.br; ceciliabial@yahoo.com.br; robertacamargoss@ \\ gmail.com; ana.paula@ufu.br; ${ }^{2}$ Universidade Federal de Goiás (UFG), Goiania-GO, Brasil; abadiadosreis@ufg.br
}

\section{RESUMO}

O crescimento do mercado de tomate para processamento industrial desperta o interesse de instituições nacionais e empresas multinacionais produtoras de sementes de hortaliças no desenvolvimento de novos híbridos. Neste sentido, objetivou-se avaliar o desempenho e a divergência genética de genótipos de tomate, quanto às características firmeza de fruto, concentração de maturação dos frutos, índice de retenção do pedúnculo, vigor da planta, cobertura foliar do fruto, sanidade da planta, produção média por planta e teor de sólidos solúveis ( ${ }^{\circ}$ Brix). Foram avaliados 53 híbridos, sendo três testemunhas, um deles o H9553, o híbrido mais plantado no Brasil. Apenas 12 genótipos e o híbrido comercial H9553 atenderam aos critérios necessários para tomates destinados ao processamento, com base nas características firmeza, concentração de maturação dos frutos e ausência de índice de retenção do pedúnculo. Os genótipos 1, 18 e 48 destacam-se quanto ao teor de sólidos solúveis, concentração de maturação e firmeza dos frutos, respectivamente. A análise de divergência genética e agrupamentos revela que os genótipos 1 e 18 apresentam maior dissimilaridade dos demais genótipos. Enquanto o primeiro demonstrou maiores médias de vigor de planta, cobertura foliar do fruto, sanidade da planta $\mathrm{e}^{\circ} \mathrm{Brix}, \mathrm{o}$ segundo revelou menores valores nas avaliações firmeza de frutos, concentração de maturação dos frutos e ${ }^{\circ}$ Brix. Os híbridos $3,6,8$, 14, 24, 37 e 48 apresentaram similaridade fenotípica com o híbrido comercial H9553, o que os caracteriza como potenciais para serem utilizados como novas opções no mercado, uma vez que apresentam alta produtividade e qualidade e, portanto, aceitabilidade na cadeia produtiva de tomate industrial. Ademais, podem ser utilizados para cruzamentos futuros com genótipos de outros grupos, que também apresentem características favoráveis.

Palavras-chave: Solanum lycopersicum, híbridos, qualidade de frutos, análise de agrupamento, ${ }^{\circ}$ Brix.

\begin{abstract}
Performance and genetic divergence of tomato genotypes for industrial processing

The growth of the tomato market for industrial processing arouses the interest of national institutions and multinational companies of vegetable seeds in the development of new hybrids. The objective of the study was evaluate the performance and genetic divergence of tomato genotypes, with respect to fruit firmness, fruit maturation concentration, jointless, plant vigor, leaf cover of the fruit, plant healthiness, average yield per plant and soluble solids ( ${ }^{\circ}$ Brix). First, we evaluated 53 hybrids, three of them being controls and one of the controls being H9553, the most sown hybrid in Brazil. Only 12 genotypes and the commercial hybrid $\mathrm{H} 9553$ presented the necessary criteria for processing tomatoes, based on characteristics fruit firmness, concentration of fruit maturation and lack of peduncle retention index. Genotypes 1, 18 and 48 stood out for soluble solids, concentration of fruit maturation and fruit firmness, respectively. The genetic divergence and groupings reveals that genotypes 1 and 18 present dissimilarity from the other genotypes. While the first showed a higher average plant vigor, leaf cover of the fruit, plant sanity and ${ }^{\circ}$ Brix, the second revealed a lower average fruit firmness, concentration of fruit maturation and ${ }^{\circ}$ Brix. Hybrid 3, 6, 8, 14, 24 , 37 and 48 showed genetic similarity with the commercial hybrid H9553, which characterizes them as potential for generating new hybrids with high productivity and quality and, consequently, with acceptability of the industrial tomato production chain. Additionally, due to their favorable characteristics, they can be used for further crosses with genotypes of other groups which also present favorable characteristics.
\end{abstract}

Keywords: Solanum lycopersicum, hybrids genotype, fruit quality, cluster analysis, ${ }^{\circ}$ Brix.

(Recebido para publicação em 5 de fevereiro de 2015; aceito em 14 de abril de 2016)

(Received on February 5, 2015; accepted on April 14, 2016)

$\mathrm{O}$ tomateiro (Solanum lycopersicum) é considerado uma das hortaliças de maior importância econômica em escala mundial. No Brasil a produção anual está em torno de 4,1 milhões de toneladas em 65 mil hectares. Os frutos obtidos são destinados tanto para o consumo in natura, quanto para o processamento na forma de suco, molho e pasta (Agrianual, 2012). O segmento de processamento industrial concentra-se em Goiás (86\%), São Paulo (12,7\%) e Minas Gerais (1,3\%), com 23 agroindústrias de atomatados (Vilela et al., 2012).

Os frutos, com grande popularidade e volume consumido, servem como uma importante fonte de nutrientes em dietas contemporâneas (Breksa et al., 2015).
Seus constituintes conferem excelente sabor, desempenham funções importantes no organismo humano, como o carotenoide licopeno, $\beta$-caroteno, ácido ascórbico e uma gama de compostos fenólicos que podem reduzir o risco de desenvolvimento de doenças cardiovasculares e retardar ou amenizar os efeitos dos radicais livres, moléculas 
instáveis que danificam as células sadias do organismo (Fontes \& Silva, 2005; Chanforana et al., 2012).

O tomate destinado à indústria tem importância significativa para os produtores devido a sua remuneração superior a de outros cultivos que são produzidos de maneira intercalada (Carvalho \& Campos, 2009). Neste segmento de produção, geralmente opta-se por plantas de crescimento determinado, devido ao seu porte reduzido e maior uniformidade de maturação, facilitando a colheita mecanizada para o processamento industrial. A característica hábito de crescimento possui herança monogênica com dominância completa do alelo SP (Self-Pruning) sobre o alelo sp (self-pruning), sendo o fenótipo hábito determinado condicionado pelo recessivo (Boiteux et al., 2012). Por outro lado, Piotto \& Peres (2012) comentam que pesquisas mais recentes têm demonstrado que o hábito de crescimento no tomateiro possui herança mais complexa.

A obtenção de genótipos superiores resulta da combinação entre parentais divergentes, os quais possuem genes que conferem melhores características de produção, qualidades organolépticas e de adaptação a estresses abióticos e bióticos (Rocha et al., 2010).

Apesar do grande potencial produtivo das cultivares disponíveis no mercado, a espécie apresenta alta suscetibilidade a uma gama de patógenos (bactérias, fungos e vírus) o que pode prejudicar o desenvolvimento da cultura e comprometer em sua totalidade a produção (Oliveira et al., 2008). Ampliar os investimentos em inovação, em busca de genótipos mais resistentes às doenças, tolerantes a pragas, eficientes na absorção de nutrientes, com ênfase em rendimento, qualidade e diferenciação de produtos, são desafios que estão colocados para o setor nos próximos anos (Brito \& Castro, 2010). Em tomateiro industrial é fundamental considerar também o teor de sólidos solúveis ( ${ }^{\circ}$ Brix), coloração do fruto, cobertura foliar, firmeza, resistência a doenças, retenção do pedúnculo na planta e produtividade.

O melhoramento genético do tomateiro no Brasil, realizado pelo setor privado, ocorre desde a década de $70 \mathrm{com}$ a introdução de cultivares e avaliação do desempenho agronômico (Boiteux et al., 2012). Essa prática ainda continua nos dias atuais, pela introdução de cultivares híbridas e, considerando as distintas condições edafoclimáticas brasileiras em relação ao local de origem do desenvolvimento dos híbridos, torna-se essencial a etapa de seleção de híbridos, com vistas a disponibilizar para o produtor novas opções de cultivo que adaptem e tolerem às doenças e pragas do país, bem como mantenha os atributos de qualidade e propriedades nutracêuticas.

Uma das etapas fundamentais no melhoramento de plantas é a identificação de genitores superiores e divergentes que permitam a obtenção de populações segregantes com maior variabilidade genética. Em tomateiro, os genitores potenciais são os acessos de banco de germoplasma, variedades e linhagens elites. Não obstante, para o desenvolvimento de novas cultivares, a seleção e uso de híbridos comerciais é uma alternativa, pois são formados por linhagens geneticamente superiores para uma ampla gama de características agronômicas e de resistência à doenças (Vogt et al., 2012). O estudo de divergência genética envolvendo híbridos para seleção de genitores tem sido relatado para espécies produtoras de grãos, olerícolas e frutíferas (Bastiane et al., 2006; Sávio et al., 2008; Aramendiz-Tatis et al., 2011; Evgenidis et al., 2011; Simon et al., 2012; Teodoro et al., 2015).

Neste sentido, objetivou-se avaliar o comportamento agronômico de genótipos de tomateiro de crescimento determinado destinado para o mercado brasileiro de processamento de frutos.

\section{MATERIAL E MÉTODOS}

Os genótipos utilizados foram híbridos de tomate de hábito de crescimento determinado desenvolvidos pela empresa Harris Moran Clause (HM. Clause), em sua estação experimental nos Estados Unidos.

Os híbridos foram obtidos a partir de um programa de melhoramento que visa atender as necessidades inerentes às condições específicas que ocorrem no Brasil, especialmente no que tange a resistências às doenças: requeima (Phytophthora infestans), pinta preta (Alternaria sp.), mancha bacteriana (Xanthomonas sp.), pinta- bacteriana (Pseudomonas syringae pv. Tomato), vira-cabeça-do-tomateiro (tospovírus) e gemivirus, uma vez que as condições climáticas do país são favoráveis para o estabelecimento e disseminação de diversos patógenos.

O ensaio foi realizado na Fazenda Barro do Capoeirão, situada no município de Inhumas, estado de Goiás ( $16^{\circ} 21^{\prime} \mathrm{S}, 4^{\circ} 29^{\prime} \mathrm{O}$, altitude $770 \mathrm{~m}$ ), em um solo predominantemente do tipo Latossolo Vermelho distroférrico.

Foram avaliados 53 genótipos, sendo três testemunhas. Os híbridos receberam códigos de 1 a 53, sendo que as testemunhas, E6203, Perfect Peel e Heinz 9553, receberam os códigos 28, 29 e 53, respectivamente. As testemunhas foram selecionadas mediante os critérios: cultivares com ampla distribuição de plantios nas principais regiões produtoras, alto potencial produtivo, uniformidade na concentração de maturação, capacidade de permanência dos frutos na planta, firmeza dos frutos e retenção do pedúnculo (Jointless).

O delineamento experimental foi de blocos ao acaso, com três repetições. As parcelas experimentais foram compostas por três linhas de plantio de tomate espaçadas em 1,20 metros, com dez plantas de tomate espaçadas em $50 \mathrm{~cm}$, em cada linha, totalizando $18 \mathrm{~m}^{2}$ de área por parcela. As linhas laterais e duas plantas de cada extremidade da linha central foram consideradas como bordaduras. As avaliações foram realizadas nas seis plantas centrais de cada parcela, o que representou uma área útil de $3,6 \mathrm{~m}^{2}$.

A área foi irrigada por pivô central. O solo foi preparado com uma aração a $25 \mathrm{~cm}$ de profundidade e gradeado duas vezes. Na sequência foi realizada a adubação de plantio com $700 \mathrm{~kg} / \mathrm{ha}$ do adubo formulação 03-34-08 (NPK)+ $8 \% \mathrm{Ca}+1,8 \% \mathrm{~S}+0,1 \% \mathrm{~B}+0,3 \% \mathrm{Mn}$.

A adubação de cobertura foi realizada após 15 dias do plantio (DAP) com $350 \mathrm{~kg} / \mathrm{ha}$ de $25-05-05$ (NPK) + 5\% S $+2 \% \mathrm{Mg} ; 370 \mathrm{~kg} / \mathrm{ha}$ de $\mathrm{KCl}(60 \%$ de $\left.\mathrm{K}_{2} \mathrm{O}\right) ; 10 \mathrm{~kg} / \mathrm{ha}$ de $07-12-40$ (NPK) + $11 \% \mathrm{~S}+2 \% \mathrm{Mg}$; e $10 \mathrm{~kg} / \mathrm{ha}$ de $20-05-05$ 
$+39 \% \mathrm{~S}+1,7 \% \mathrm{Mg}$.

O semeio foi realizado no dia 07 de abril de 2010 no Viveiro Emra, localizado em Hidrolândia-GO. Após o semeio as bandejas permaneceram 4 dias na estufa de germinação, mantendo uma temperatura de $21^{\circ} \mathrm{C}$ e umidade de $75 \%$. Terminado esse período, as mudas foram levadas para as estufas, onde permaneceram até o transplante.

O transplante das mudas para o campo ocorreu no dia 12 de maio de 2010, plantando-se uma muda por cova, manualmente.

Para a colheita e avaliação do experimento foi observado o momento em que a maioria dos híbridos atingiram uma quantidade ideal de frutos maduros, o que aconteceu nos dias 14, 15 e 16 de setembro de 2010, aos 160 dias após a semeadura (DAS) e 125 dias após o transplante (DAT), no qual os frutos se encontravam com coloração vermelho intenso.

A primeira etapa de avaliação foi de carácter eliminatório. Desta forma, os híbridos com nota média dos frutos inferior a 3 pontos, para firmeza do fruto, concentração de maturação e classificados como jointless para índice de retenção do pedúnculo foram descartados e não participaram das análises posteriores.

Frutos muito macios, com baixa concentração de maturação, bem como os que possuíram a característica jointless (retenção do pedúnculo) são indesejáveis para o processamento, o que justificou sua eliminação.

A firmeza dos frutos de tomate foi mensurada pela compressão do fruto com a ponta dos dedos. Adotou-se uma escala que variou entre fruto muito macio (nota 1), macio (2), médio (3), firme (4) e muito firme (5). Frutos muito macios amassaram com facilidade, ao passo que frutos muito firmes resistiram à pressão física e não apresentaram deformações.

Em cultivos em que a colheita é mecanizada, faz-se necessário que o maior número de frutos atinja o ponto ideal de colheita (maturação no desenvolvimento) em um mesmo intervalo de tempo. Assim, foram atribuídas, visualmente, notas de 1 a 5 , referentes a genótipos com muito baixa (1), baixa (2), média (3), alta (4) e muito alta (5) concentração de maturação.

A avaliação do nível de retenção foi realizada a partir de duas plantas inteiras de cada parcela. As plantas foram acondicionadas em sacos plásticos, os quais foram sacudidos até que todos os frutos presentes nas plantas se desprendessem. Híbridos que apresentaram pedúnculos retidos aos frutos foram descartados.

Os híbridos que apresentaram características favoráveis na primeira etapa de avaliação foram classificados em níveis (notas de 1 a 5) quanto às seguintes características: vigor da planta, cobertura foliar do fruto e sanidade da planta. Também foi mensurada a produção média por planta e teor de sólidos solúveis ( ${ }^{\circ}$ Brix).

As plantas foram avaliadas visualmente, em análise do diâmetro dos ramos. Foram atribuídas notas de 1 a 5 referentes a vigor muito baixo (1), baixo (2), médio (3), alto (4) e muito alto (5).

A cobertura foliar do fruto foi avaliada, observando-se a exposição dos frutos ao sol. Frutos muito expostos não atingem a coloração adequada e depreciam a qualidade da polpa no momento do processamento. Foram atribuídas notas de 1 a 5 que variam de cobertura foliar muito ruim (1), ruim (2), média (3), boa (4) e muito boa (5).

Quanto à incidência de doenças em toda a planta (folhas, ramos e frutos), os índices variaram de muito baixa (1), baixa (2), média (3), alta (4) a muito alta (5) sanidade da planta.

Foram pesados todos os frutos ideais para processamento, ou seja, aqueles que estavam com a coloração vermelha, de três plantas por parcela. O peso total foi divido por três, obtendo-se a produção média por planta.

Foram colhidos aleatoriamente dez frutos de cada parcela útil de todos os genótipos classificados na primeira etapa da avaliação. Para análise de sólidos solúveis utilizou-se um refratômetro digital, para o qual foi transferido uma gota de sumo de cada fruto e determinado o ${ }^{\circ}$ Brix.

Os dados foram submetidos à análise de variância (ANOVA), e quando detectada variabilidade genética entre os híbridos, as médias foram agrupadas pelo teste Scott-Knott. As análises foram realizadas no Programa GENES (Aplicativo Computacional em Genética e Estatística Experimental) (Cruz, 2013).

Os dados dos híbridos não descartados foram utilizados para estudo de divergência fenotípica entre os híbridos do tomateiro, com base em sete caracteres (firmeza de frutos, concentração de maturação, vigor de planta, cobertura foliar, sanidade, produção e ${ }^{\circ}$ Brix).

Considerando as médias dos valores fenotípicos dos sete caracteres estudados, foi obtida a distância generalizada de Mahalanobis entre os híbridos que passaram pela fase de pré-seleção. Posteriormente, obteve-se um dendrograma pela método da ligação média entre grupo [Unweighted Pair-Group Method using Arithmetic Averages (UPGMA)] e, também, realizou-se o agrupamento dos genótipos pelo método de otimização de Tocher. Os critérios adotados para obter o dendrograma e agrupamento estão descritos em Cruz et al. (2011).

Foi determinada a contribuição relativa das características na dissimilaridade dos genótipos pela metodologia de Singh (1981).

\section{RESULTADOS E DISCUSSÃO}

Entre os 53 híbridos avaliados, apenas os híbridos 1, 2, 3, 4, 6, 8, 14, 18, $24,30,37,48$ e 53 foram classificados para a segunda etapa de avaliação (Tabela 1). Os demais foram descartados devido à inadequação das características principais necessárias ao processamento dos frutos de tomate, ou seja, somente os híbridos que apresentaram firmeza do fruto suficiente para resistir aos impactos da colheita mecânica como a do transporte até a indústria, concentração de maturação dos frutos em um mesmo período e retenção do pendúculo permaneceram para as análises subsequentes.

A seleção inicial é essencial, pois maximiza a produção de frutos efetivos para o processamento e a inclusão do gene que confere ou influencia na característica retenção do pedúnculo, jointless e arthritic, respectivamente. A ausência de "joelho" faz com que o pedúnculo 
Tabela 1. Classificação dos genótipos quanto à firmeza de fruto (FF), concentração de maturação dos frutos (CMF) e índice de retenção do pedúnculo (IRP) \{classification of genotypes on fruit firmness $(\mathrm{FF})$, fruit maturation concentration (CMF) and peduncle retention index (IRP)\}. Uberlândia, UFU, 2011.

\begin{tabular}{|c|c|c|c|c|}
\hline Genótipo & FF & CMF & IRP & Conclusão \\
\hline 1 & 4,00 & 3,00 & Arthritic & Classificado \\
\hline 2 & 3,67 & 4,00 & Arthritic & Classificado \\
\hline 3 & 3,67 & 4,00 & Arthritic & Classificado \\
\hline 4 & 3,00 & 3,33 & Arthritic & Classificado \\
\hline 5 & 3,67 & 4,00 & Jointed & Descartado \\
\hline 6 & 3,33 & 3,67 & Jointless & Classificado \\
\hline 7 & 2,33 & & & Descartado \\
\hline 8 & 4,00 & 4,00 & Arthritic & Classificado \\
\hline 9 & 4,00 & 2,33 & & Descartado \\
\hline 10 & 2,33 & & & Descartado \\
\hline 11 & 2,33 & & & Descartado \\
\hline 12 & 3,33 & 2,33 & & Descartado \\
\hline 13 & 3,00 & 2,33 & & Descartado \\
\hline 14 & 3,67 & 4,00 & Arthritic & Classificado \\
\hline 15 & 2,33 & & & Descartado \\
\hline 16 & 4,00 & 2,33 & & Descartado \\
\hline 17 & 4,00 & 2,00 & & Descartado \\
\hline 18 & 4,00 & 4,33 & Jointless & Classificado \\
\hline 19 & 2,33 & & & Descartado \\
\hline 20 & 3,00 & 2,67 & & Descartado \\
\hline 21 & 3,67 & 2,00 & & Descartado \\
\hline 22 & 2,67 & & & Descartado \\
\hline 23 & 2,00 & & & Descartado \\
\hline 24 & 4,00 & 4,00 & Arthritic & Classificado \\
\hline 25 & 1,33 & & & Descartado \\
\hline 26 & 3,33 & 2,67 & & Descartado \\
\hline 27 & 2,00 & & & Descartado \\
\hline 28 & 1,00 & & & Descartado \\
\hline 29 & 2,33 & & & Descartado \\
\hline 30 & 3,33 & 4,00 & Arthritic & Classificado \\
\hline 31 & 2,67 & 2,67 & & Descartado \\
\hline 32 & 3,67 & 2,00 & & Descartado \\
\hline 33 & 3,00 & 2,67 & & Descartado \\
\hline 34 & 1,67 & & & Descartado \\
\hline 35 & 2,00 & & & Descartado \\
\hline 36 & 2,00 & & & Descartado \\
\hline 37 & 4,00 & 3,33 & Jointless & Classificado \\
\hline 38 & 2,00 & & & Descartado \\
\hline 39 & 2,00 & & & Descartado \\
\hline 40 & 3,67 & 2,33 & & Descartado \\
\hline 41 & 4,00 & 4,00 & Jointed & Descartado \\
\hline 42 & 2,67 & 2,67 & & Descartado \\
\hline 43 & 4,00 & 2,00 & & Descartado \\
\hline 44 & 1,67 & & & Descartado \\
\hline 45 & 1,67 & & & Descartado \\
\hline 46 & 1,67 & & & Descartado \\
\hline 47 & 4,00 & 2,33 & & Descartado \\
\hline 48 & 4,33 & 4,00 & Jointless & Classificado \\
\hline 49 & 2,00 & & & Descartado \\
\hline 50 & 2,33 & & & Descartado \\
\hline 51 & 2,33 & & & Descartado \\
\hline 52 & 3,00 & 2,67 & & Descartado \\
\hline 53 & 4,00 & 4,00 & Arthritic & Classificado \\
\hline
\end{tabular}

FF com notas variando de 1 a 5 onde $1=$ muito macio e $5=$ muito firme; CMF com notas variando de 1 a 5 onde $1=$ muito baixa e $5=$ muito alta $(\mathrm{FF}$ evaluated with grades varying from 1 to 5 where $1=$ very soft and $5=$ highly firm; CMF with grades varying from 1 to 5 where $1=$ low concentration and $5=$ highly concentrated). fique aderido à planta, o que facilita $o$ processo de colheita, uma vez que evita o trabalho de remoção dos pedúnculos na linha de processamento.

Dos 13 híbridos restantes, o híbrido 48 apresentou numericamente a maior média de firmeza $(4,33)$, com frutos firmes a muito firmes, o qual não se diferiu significativamente dos híbridos $1 ; 8 ; 18$; 24; 37 e 53, que revelaram frutos firmes, e, portanto, com boa qualidade para serem enviados para o processamento industrial (Tabela 2).

Frutos com média firmeza a firmes $(3,0$ a 3,67$)$ caracterizaram os demais híbridos. É importante lembrar que, frutos com média firmeza $(3,00)$ implicam razoável resistência dos frutos aos impactos, o que pode gerar perdas no intervalo entre a colheita e o beneficiamento para obtenção dos produtos industrializados (Tabela 2).

Quanto à concentração de maturação dos frutos, apenas os híbridos 1, 4 e 37 demonstraram média concentração de maturação. Os demais híbridos revelaram alta uniformidade das plantas, com a maioria dos frutos com estádio de maturação em um mesmo período de tempo, o que facilitou diversas operações, em especial a colheita (Tabela 2).

Segundo Aragão et al. (2004), estudos têm demonstrado que existe uma correlação entre o ciclo do tomateiro com a firmeza e o teor de sólido solúveis dos frutos, em que cultivares mais precoces apresentam menor firmeza de frutos e teor de sólidos solúveis.

$\mathrm{O}$ vigor e a sanidade das plantas, cobertura foliar do fruto e produção média por planta não se diferiram entre os híbridos avaliados (Tabela 2). As plantas apresentaram vigor de médio a muito alto, a cobertura foliar do fruto e a sanidade das plantas variaram entre baixa a alta, com produção média de 4,07 a $6,02 \mathrm{~kg} / \mathrm{planta}$ de frutos.

Para o teor de sólidos solúveis, apesar de ter sido classificado como baixo em todos os híbridos devido a interferência do clima e dos manejos da irrigação e adubação, observou-se destaque destes constituintes no híbrido 1 $(4,60)$ e menor quantidade no genótipo 4 $(3,87)$. Os demais híbridos não diferiram entre si (Tabela 2).

A produção do tomateiro é uma das 
características mais importantes e essenciais objetivadas no melhoramento, no entanto, é de herança poligênica, apresentando alta influência ambiental. A capacidade de produção está em função do efeito do genótipo de cada cultivar, das condições ambientais de cultivo e da interação entre ambos (Jidavu et al., 2006).

Seleguini et al. (2007) afirmaram que a melhor maneira das cultivares de tomate industrial aumentarem a produtividade é por meio do acréscimo do número de frutos por planta. Figueiredo (2013), em estudo com linhagens de tomateiro com aptidão industrial também observou a relação entre maior número de frutos produzidos por planta e produtividade.

A maioria das cultivares de tomateiro disponíveis no mercado para industrialização apresentam valores de sólidos solúveis próximo de $4,5^{\circ}$ Brix, valor considerado baixo diante das necessidades industriais, que preza como ideal $5^{\circ}$ Brix (Melo \& Vilela, 2005) e neste sentido, atualmente os melhoristas têm trabalhado na busca de variedades que acumulem mais sólidos solúveis, conforme alguns genótipos apresentaram neste trabalho.

A resposta de um genótipo quanto à sanidade das plantas auxilia no posicionamento da melhor época em que cada genótipo deve ser plantado. Dentre as condições climáticas, períodos chuvosos determinam a tomada de decisão pelo alto grau de relação com as doenças (requeima, alternaria, xantomonas, pseudomonas, vira cabeça e gemivirus). Isto foi observado no resultado da testemunha deste trabalho, que apresentou nota de sanidade baixa, visto que este híbrido é posicionado comercialmente para ser conduzidos em épocas não chuvosas. Alguns híbridos experimentais (1 e 30) revelaram média 4 para esta característica, logo destacam-se pelo potencial genético desses materiais em resistirem à pressão de doenças, principalmente bacterianas.

Para Melo \& Vilena (2005), o desenvolvimento de híbridos com resistência genética aos patógenos, além de ser a solução mais racional do ponto de vista ambiental, pode proporcionar o crescimento da agroindústria do tomate

Tabela 2. Firmeza de fruto (FF), concentração de maturação dos frutos (CMF), vigor da planta (VP), cobertura foliar do fruto $(\mathrm{CFF})$, sanidade da planta $(\mathrm{S})$, produção média por planta $(\mathrm{P})$ e teor de sólidos solúveis $\left({ }^{\circ} \mathrm{Brix}\right)$ dos genótipos classificados \{fruit firmness (FF), fruit maturation concentration (CMF), plant vigor (VP), leaf cover of the fruit (CFF), plant health $(\mathrm{S})$, average yield per plant $(\mathrm{P})$ and soluble solids ( $\left.{ }^{\circ} \mathrm{Brix}\right)$ of classified genotypes . Uberlândia, UFU, 2011.

\begin{tabular}{lccccccc}
\hline Genótipo & FF & CMF & VP & CFF & S & P (kg/planta) & ${ }^{\circ}$ Brix \\
\hline 1 & $4,00 \mathrm{a}$ & $3,00 \mathrm{~b}$ & $4,00 \mathrm{a} *$ & $4,00 \mathrm{a}$ & $4,00 \mathrm{a}$ & $4,42 \mathrm{a}$ & $4,60 \mathrm{a}$ \\
2 & $3,67 \mathrm{~b}$ & $4,00 \mathrm{a}$ & $3,67 \mathrm{a}$ & $2,33 \mathrm{a}$ & $2,33 \mathrm{a}$ & $5,32 \mathrm{a}$ & $3,97 \mathrm{ab}$ \\
3 & $3,67 \mathrm{~b}$ & $4,00 \mathrm{a}$ & $3,67 \mathrm{a}$ & $3,33 \mathrm{a}$ & $3,33 \mathrm{a}$ & $4,07 \mathrm{a}$ & $4,17 \mathrm{ab}$ \\
4 & $3,00 \mathrm{~b}$ & $3,33 \mathrm{~b}$ & $3,33 \mathrm{a}$ & $3,67 \mathrm{a}$ & $3,33 \mathrm{a}$ & $4,93 \mathrm{a}$ & $3,87 \mathrm{~b}$ \\
6 & $3,33 \mathrm{~b}$ & $3,67 \mathrm{a}$ & $3,33 \mathrm{a}$ & $3,33 \mathrm{a}$ & $3,00 \mathrm{a}$ & $5,37 \mathrm{a}$ & $4,20 \mathrm{ab}$ \\
8 & $4,00 \mathrm{a}$ & $4,00 \mathrm{a}$ & $3,33 \mathrm{a}$ & $2,67 \mathrm{a}$ & $2,67 \mathrm{a}$ & $5,67 \mathrm{a}$ & $4,50 \mathrm{ab}$ \\
14 & $3,67 \mathrm{~b}$ & $4,00 \mathrm{a}$ & $3,67 \mathrm{a}$ & $3,33 \mathrm{a}$ & $3,67 \mathrm{a}$ & $5,67 \mathrm{a}$ & $4,27 \mathrm{ab}$ \\
18 & $4,00 \mathrm{a}$ & $4,33 \mathrm{a}$ & $4,33 \mathrm{a}$ & $4,00 \mathrm{a}$ & $3,67 \mathrm{a}$ & $5,22 \mathrm{a}$ & $4,03 \mathrm{ab}$ \\
24 & $4,00 \mathrm{a}$ & $4,00 \mathrm{a}$ & $3,00 \mathrm{a}$ & $3,33 \mathrm{a}$ & $2,67 \mathrm{a}$ & $6,02 \mathrm{a}$ & $4,10 \mathrm{ab}$ \\
30 & $3,33 \mathrm{~b}$ & $4,00 \mathrm{a}$ & $4,00 \mathrm{a}$ & $3,33 \mathrm{a}$ & $4,00 \mathrm{a}$ & $5,65 \mathrm{a}$ & $4,13 \mathrm{ab}$ \\
37 & $4,00 \mathrm{a}$ & $3,33 \mathrm{~b}$ & $3,67 \mathrm{a}$ & $3,00 \mathrm{a}$ & $3,33 \mathrm{a}$ & $5,28 \mathrm{a}$ & $4,23 \mathrm{ab}$ \\
48 & $4,33 \mathrm{a}$ & $4,00 \mathrm{a}$ & $3,67 \mathrm{a}$ & $3,33 \mathrm{a}$ & $3,00 \mathrm{a}$ & $5,08 \mathrm{a}$ & $4,33 \mathrm{ab}$ \\
53 & $4,00 \mathrm{a}$ & $4,00 \mathrm{a}$ & $4,67 \mathrm{a}$ & $3,67 \mathrm{a}$ & $3,00 \mathrm{a}$ & $4,17 \mathrm{a}$ & $4,33 \mathrm{ab}$ \\
\hline CV (\%) & 10,02 & 8,38 & 15,23 & 21,62 & 22,67 & 21,03 & 5,04 \\
\hline
\end{tabular}

FF com notas variando de 1 a 5 onde $1=$ muito macio e $5=$ muito firme; CMF com notas variando de 1 a 5 onde $1=$ muito baixa e $5=$ muito alta; VP com notas variando de 1 a 5 onde $1=$ muito baixo e $5=$ alto; CFF com notas variando de 1 a 5 onde $1=$ muito ruim e $5=$ muito boa; $\mathrm{S}$ com notas variando de 1 a 5 onde $1=$ muito baixa e $5=$ muito alta (FF evaluated with grades varying from 1 to 5 where $1=$ very soft and $5=$ highly firm; CMF with grades varying from 1 to 5 where $1=$ low concentration and $5=$ highly concentrated; VP with grades varying from 1 to 5 where $1=$ low vigor and $5=$ high vigor; CFF with grades varying from 1 to 5 where $1=$ poorly concentrated and $5=$ highly concentrated; $S$ with grades varying from 1 to 5 where $1=$ very low sanity and $5=$ very good sanity); Médias com a mesma letra na coluna não diferem entre si pelo teste Scott-Knott ao nível de 0,05 de significância (means with the same letter in the column do not differ by Scott Knott test, 5\%).

Tabela 3. Agrupamento de híbridos de tomateiro pelo método de otimização de Tocher, a partir das distâncias generalizadas de Mahalanobis (grouping of tomato hybrids using the optimization Tocher method, from the generalized Mahalanobis distances). Uberlândia, UFU, 2011.

\begin{tabular}{lc}
\hline Grupo & Genótipos \\
\hline I & $3,6,8,14,24,37,48,53$ \\
II & $2,18,30$ \\
III & 4 \\
IV & 1 \\
\hline
\end{tabular}

no Cerrado nas próximas décadas, o que maximiza a eficiência dos fatores econômicos e ambientais.

As informações obtidas por meio da avaliação de um conjunto de híbridos são ferramentas importantes na seleção de novas cultivares superiores, o que contribui para a oferta de novos materiais potenciais no mercado de tomate para processamento (Aragão et al., 2004).

Pela dissimilaridade genética entre os híbridos, com base nos caracteres avaliados (firmeza de fruto, concentração de maturação dos frutos, vigor da planta, cobertura foliar do fruto, sanidade da planta, produção e ${ }^{\circ}$ Brix), verificou-se que os híbridos mais similares foram os híbridos 8 e 48, cujo valor de $\mathrm{D}^{2}$ foi de 2,95 . Por outro lado, 


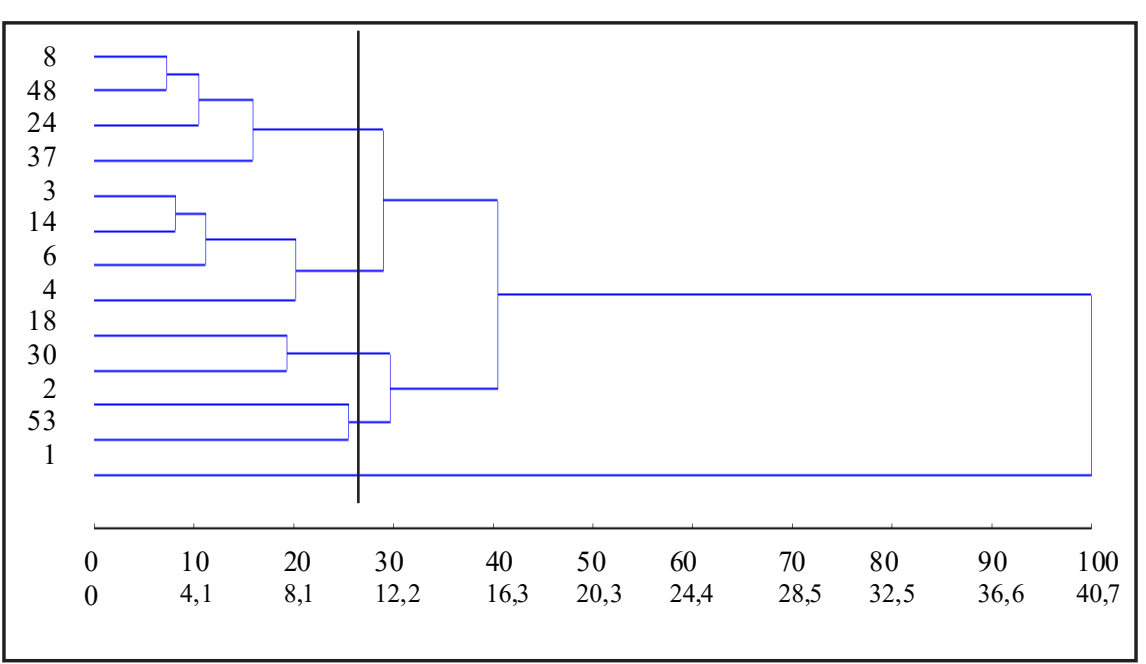

Figura 1. Dendrograma ilustrativo da análise de 13 genótipos de tomate pelo método da ligação média entre grupo (UPGMA) obtido com a distância generalizada de Mahalanobis gerada com sete caracteres (firmeza de fruto, concentração de maturação dos frutos, vigor da planta, cobertura foliar do fruto, sanidade da planta, produção e ${ }^{\circ}$ Brix ) \{illustrative dendrogram analysis of 13 tomato genotypes by the average linkage method between group (UPGMA) obtained with the generalized distance of Mahalanobis generated with seven characters (fruit firmness, fruit maturation concentration, plant vigor, leaf cover of the fruit, plant health, production and ${ }^{\circ}$ Brix $\left.)\right\}$; Coeficiente de correlação cofenética $(\mathrm{r})=0,76^{* *}$. Distorção= 16,9\%. (cophenetic correlation coefficient $(r)=0,76^{* *}$. Distortion=16,9\%). Uberlândia, UFU, 2011.

a maior dissimilaridade genética de 75,42 foi verificada entre os híbridos 1 e 18 (Tabela 3).

O estudo da diversidade intraespecífica visa atender à crescente demanda mundial por alimentos, além de manter a capacidade da espécie para lidar com o clima, mudanças e outros tipos de estresse (Castro et al., 2010). Além disso, permite selecionar os melhores genitores sem a necessidade de avaliação direta de sua descendência (Faleiro, 2007).

O foco nos híbridos promissores, acelera as etapas dentro do programa de melhoramento genético. Desta forma, quanto menor o grau de parentesco entre dois genitores, maior será o número de locus divergentes, e consequentemente menor similaridade genética entre estes indivíduos (Cruz, 2010).

Utilizando a matriz de dissimilaridade de Mahalanobis para gerar o dendrograma pelo método UPGMA, obteve-se um coeficiente de correlação cofenética de 0,76 e distorção de $16,9 \%$, o que evidencia uma adequada relação entre a matriz de distância e o dendrograma gerado (Figura 1).

Para análise do dendrograma, considerou-se a possibilidade de corte significativo, conjuntamente com o exame visual do dendrograma. Um corte significativo em torno de $27 \%$ de dissimilaridade possibilitou a formação de cinco grupos distintos.

O grupo I reuniu os híbridos 8 , 48, 24 e 37, o grupo II foi constituído pelos híbridos 3, 14, 6 e 4, o grupo III foi composto pelos híbridos 18 e 30, o grupo IV pelos híbridos 2 e 53 e o grupo $\mathrm{V}$ compilou apenas o híbrido 1 (Figura 1). Ao observar as médias de cada variável analisada, nota-se que o híbrido 1 revelou os maiores valores quanto ao sanidade da planta e ${ }^{\circ}$ Brix.

$\mathrm{O}$ agrupamento dos 13 híbridos de tomate pelo método de Tocher, com a utilização da distância generalizada de Mahalanobis como medida de distância genética, obtida com sete caracteres agronômicos, gerou a formação de quatro grupos: I: híbridos $3,6,8,14$, 24, 37, 48, 53; II: genótipo 2, 18, 30; III: genótipo 4 e IV: genótipo 1 (Tabela 3 ).

O grupo I teve o maior número de representantes, seguido pelo grupo II. Por este método, houve consideráveis alterações na forma de agrupamento dos híbridos, especialmente com a segregavigor de planta, cobertura foliar do fruto, ção do genótipo 4. Em análise do teste de médias, observou-se que o híbrido 4 apresentou notas inferiores para firmeza de frutos, concentração de maturação dos frutos $\mathrm{e}^{\circ}$ Brix. Este método também posicionou o híbrido 53 (Heinz 9553) para o grupo I. A similaridade genética entre os híbridos deste programa de melhoramento e o híbrido 53 evidenciou uma possível relação entre os materiais.

$\mathrm{O}$ fato de existirem acessos semelhantes às cultivares comerciais é interessante, pois, permite a incorporação de algum atributo positivo, como a resistência a pragas ou doenças, sem afetar significativamente os caracteres relevantes obtidos ao longo dos programas de melhoramento (Marim et al., 2009).

O critério de seleção pelo método de Tocher agrupa a maioria dos acessos em poucos grupos, e, em híbridos com maior dissimilaridade, formam-se grupos com apenas um genótipo. Isso ocorre devido ao agrupamento ser influenciado pela distância entre os híbridos, o qual considera a maior entre as menores distâncias encontradas na matriz de dissimilaridade (Vasconcelos et al., 2007). Este aspecto fora observado neste estudo, com a formação dos grupos III e IV, com apenas um genótipo por grupo.

Azevedo et al. (2014), em estudo da divergência entre genótipos de couve também observaram predominância dos genótipos em um grupo (77\%) e formação de grupos com apenas um genótipo, quando utilizou-se o método de Tocher. Os autores salientaram que, embora haja genótipos com grande divergência genética entre si, o agrupamento da maioria dos genótipos em um grupo evidencia a similaridade entre os genótipos, o que, de acordo com Silva et al. (2011), refere-se a uma base genética estreita.

O método de Tocher, tem sido utilizado em estudos de divergência genética em várias olerícolas como a alface (Oliveira et al., 2004), a melancia (Souza et al., 2005), pimenta e pimentão (Sudré et al., 2005), melão "pele de sapo" (Nunes et al., 2011a) e melão do grupo Inodorus (Nunes et al., 2011b).

Com relação à contribuição relativa dos caracteres para diversidade pelo 
método de Sing (1981), observou-se que a firmeza de frutos, concentração de maturação, vigor de planta, cobertura foliar, sanidade, produção e ${ }^{\circ}$ Brix contribuíram com 16,$9 ; 33,9 ; 9,9 ; 5,2 ; 6,8 ; 3,9$ e $23,3 \%$, respectivamente. Portanto, a característica concentração de maturação $\mathrm{e}^{\circ} \mathrm{Brix}$ foram as que mais contribuíram para dissimilaridade genética.

Figueiredo (2013) também relatou o teor de sólidos solúveis como um dos fatores que mais contribuíram para a dissimilaridade entre híbridos ou linhagens.

Concluiu-se que apenas 12 híbridos experimentais e o híbrido comercial H9553 atendem aos critérios necessários para tomates destinados ao processamento, com base nas características: firmeza, concentração de maturação dos frutos e ausência de índice de retenção do pedúnculo. Os híbridos 1, 18 e 48 destacaram-se quanto ao teor de sólidos solúveis, concentração de maturação e firmeza dos frutos, respectivamente.

A análise de divergência genética e agrupamentos revela que os híbridos 1 e 18 apresentam dissimilaridade dos demais híbridos. Sendo que o primeiro demonstrou maiores médias de vigor de planta, cobertura foliar do fruto, sanidade da planta $\mathrm{e}^{\circ} \mathrm{Brix}$, o segundo revela menores médias para firmeza de frutos, concentração de maturação dos frutos $\mathrm{e}^{\circ}$ Brix.

Os híbridos 3, 6, 8, 14, 24, 37 e 48 apresentam similaridade genética com o híbrido comercial H9553, o que os caracteriza como potenciais para serem utilizados como novas opções no mercado, uma vez que apresentam alta produtividade, qualidade e, portanto, aceitabilidade na cadeia produtiva de tomate industrial. Além disso, podem ser utilizados para cruzamentos futuros com híbridos de outros grupos, que também apresentem características favoráveis.

\section{AGRADECIMENTOS}

Os autores agradeçem à FAPEMIG pelo apoio financeiro ao presente trabalho.

\section{REFERÊNCIAS}

AGRIANUAL. 2012. Batata. São Paulo: FNP. 482p.

ARAGÃO, FAS; GIORDANO, LB; MELO, PCT; BOITEUX, LS. 2004. Desempenho de híbrido de tomateiro para processamento industrial. Horticultura Brasileira 22: 529-533.

ARAMENDIZ-TATIS, H; SUDRÉ, CP; GONÇALVES, LSA; RODRIGUES, R. 2011. Potencial agronômico e divergência genética entre genótipos de berinjela nas condições do Caribe Colombiano. Horticultura Brasileira 24: 174-180.

AZEVEDO, AM; ANDRADE JÚNIOR, VC; FERNANDES, JSC; PEDROSA, CE; VALADARES, NR; FERREIRA, MAM; MARTINS, RAV. 2014. Divergência genética e importância de caracteres morfológicos em genótipos de couve. Horticultura Brasileira 32: 48-54.

BASTIANE, M; OLIVEIRA, AC; CRISTOFANI, M; MACHADO, MA. 2006. Diversidade genética entre híbridos de laranja-doce e tangor 'Murcott' avaliada por fAFLP e RAPD. Pesquisa Agropecuária Brasileira 41: 779-784.

BOITEUX, LS; FONSECA, MEN; GIORDANO, LB; MELO, PCT. 2012. Melhoramento genético. In: CLEMENTE, FMVT; BOITEUX, LS. (eds). Produção de tomate para processamento industrial. Brasília: Embrapa. p. 31-50.

BREKSA, AP; ROBERTSONB, LD; LABATE, JA; KING, BA，KING, DE. 2015. Physicochemical and morphological analysis of ten tomato varieties identifies quality traits more readily manipulated through breeding and traditional selection methods. Journal of Food Composition and Analysis 42: 16-25.

BRITO, L; CASTRO, SD. 2010. Expansão da produção de tomate industrial no Brasil e em Goiás. Boletim da Seplan. Disponível em: http://www.seplan.go.gov.br/Acessado em 01 de janeiro de. 2012.

CARVALHO, CRR; CAMPOS, FR. 2009. Análise dos aspectos econômicos e ambientais da cadeia agroindustrial do tomate no estado de Goiás. Boletim Goiano de Geografia 29: 163-168.

CASTRO, JPA; NICKI, C; MILAGRES, CCA; MATTEDI, AP; MARIM, BG; SILVA, DJH. 2010. Genetic diversity among tomato's subsamples for prebreeding. Crop Breeding and Applied Biotechnology 10: 74-82.

CHANFORANA, C; LOONISA, M; MORAA, $\mathrm{N}$; CARIS-VEYRATA, C; DUFOUR, C. 2012. The impact of industrial processing on health-beneficial tomato microconstituents. Food Chemistry 134: 1786-1795.

CRUZ, CD. 2010. Principios de genética quantitativa. Viçosa: UFV. 394p. (1a reimpressão).

CRUZ, CD. 2013. Genes: a software package for analysis in experimental statistics and quantitative genetics. Acta Scientiarum Agronomy 3: 271-276.

CRUZ, CD; FERREIRA, FM; PESSONI, LA. 2011. Biometria aplicada ao estudo de diversidade genética. Viçosa: UFV. 620p.

EVGENIDIS, G; TRAKA-MAVRONA, E; KOUTSIKA-SOTIRIOU, M. 2011. Analysis as a tool in the assessment of tomato hybrids and cultivars. International Journal of Agronomy Article ID 697879, 7p.

FALEIRO, FG. 2007. Marcadores GenéticoMoleculares. Brasília: EMBRAPA. 102p.

FIGUEIREDO, AST. 2013. Capacidade de combinação e divergência genética de linhagens de tomateiro com aptidão industrial. Guarapuava: UNIOESTE. 98p (Dissertação mestrado).

FONTES, PCR; SILVA, DJH. 2005. Cultura do tomate. In: FONTES, PCR (ed). Olericultura: Teoria e Prática. Viçosa. p. 458-475.

JIDAVU, M; SESTRA, R.; APAHIDEAN, M; SESTRA, A. 2006. The response of several tomato cultivars for processing in central Transylvania conditions. Notulae Botanicae Horti Agrobotanici Cluj-Napoca 54-61.

MARIM, BG; SILVA, DJH; CARNEIRO, PCS; MIRANDA, GV; MATTEDI, AP; CALIMAN, FRB. 2009. Variabilidade genética e importância relativa de caracteres em acessos de germoplasma de tomateiro. Pesquisa Agropecuária Brasileira 44: 12831290.

MELO, PCT; VILELA, NJ. 2005. Desafio e perspectivas para a cadeia brasileira do tomate para processamento industrial. Horticultura Brasileira 23: 154-157.

NUNES, GH; COSTA FILHO, JA; SILVA, DJH; CARNEIRO, PCS; DANTAS, DJ. 2011a. Divergência genética entre linhagens de melão Pele de Sapo. Revista Ciência Agronômica 42: 765-773.

NUNES, GH; MELO, DRM; DANTAS, DJ; ARAGÃO, FAS; NUNES, EWL. 2011 b. Divergência genética entre linhagens de melão do grupo Inodorus. Revista Ciência Agronômica 42: 448-456.

OLIVEIRA, ACB; SEDIYAMA, MAN; PEDROSA, MW; GARCIA, NCP; GARCIA, SLR. 2004. Divergência genética e descarte de variáveis em alface cultivada sob sistema hidropônico. Acta Scientiarum 26: 211-217.

OLIVEIRA, ACR; VELOSO, VRS; BARROS, RG; FERNANDES, PM; SOUZA, ERB. 2008. Captura de Tuta absoluta (Meyrick) (Lepidoptera: Gelechiidae) com armadilha luminosa na cultura do tomateiro tutorado. Pesquisa Agropecuária Tropical 38: 153-157.

PIOTTO, FA; PERES, LEP. 2012. Base genética do hábito de crescimento e florescimento em tomateiro e sua importância na agricultura. Ciência Rural 42: 1941-1946.

ROCHA, MC; GONÇALVES, LSA; RODRIGUES, R; SILVA, PRA; CARMO, MGF; ABBOUD, ACS. 2010. Uso do algoritmo de Gower na determinação da divergência genética entre acessos de tomateiro do grupo cereja. Acta Scientiarum 32: 423-431.

SÁVIO, FL; FARIA, PN; PEREIRA, WA; OLIVEIRA, AB; TARDIN, FD; RODRIGUES, JAS; SCHAFFERT, RE. 2008. Divergência genética em híbridos de sorgo cultivados sob diferentes níveis de fósforo, em solução nutritiva. Revista Brasileira de Milho e Sorgo 7: 305-321.

SELEGUINI, A; SENO, S; FARIA JÚNIOR, MJA. 2007. Híbridos de tomateiro industrial cultivado em ambiente protegido e campo aberto. Cientifica 35: 80-87. 
SILVA, GC; OLIVEIRA, FJ; ANUNCIAÇÃO FILHO, CJ; NETO, DES; MELO, LJOT. 2011. Divergência genética entre genótipos de cana de açúcar. Revista Brasileira de Ciências Agrárias 6: 52-58.

SIMON, GA; KAMADA, T; MONTEIRO, M. 2012. Divergência genética em milho de primeira e segunda safra. Semina 33: 449-458.

SINGH, D. 1981. The relative importance of characters affecting genetic divergence. Indian Journal of Genetics and Plant Breeding 41: 237-2145.

SOUZA, FF; QUEIRO,Z MA; DIAS, RSC. 2005. Divergência genética em linhagens de melancia. Horticultura Brasileira 23: 179-183.

SUDRÉ, CP; RODRIGUES, R; RIVA, EM; KARASAWA, M; AMARAL JÚNIOR, AT. 2005. Divergência genética entre acessos de pimenta e pimentão utilizando técnicas multivariadas. Horticultura Brasileira 23: 22-27.

TEODORO, PE; RIBEIRO, LP; CORREA, CCG; SILVA, FA; CAPRISTO, DP; MARQUES, RA; SOUZA, MC; TORRES, FE. 2015. Genetic divergence among maize hybrids in Cerrado pantanal Ecotone. Bioscience Journal 31: 1319-1324.

VASCONCELOS, ES; CRUZ, CD; BHERING,
LL; RESENDE JÚNIOR, MFR. 2007. Método alternativo para análise de agrupamento. Pesquisa Agropecuária Brasileira 42: 1421 1428.

VILELA, NJ; MELO, PCT; BOITEUX, LS; CLEMENTE, FMVT. 2012. Melhoramento genético. In: CLEMENTE, FMVT; BOITEUX, LS (eds). Produção de tomate para processamento industrial. Brasília: Embrapa. 1: 17-27.

VOGT, GA; ELIAS, HT; STAFORT, R; BALBINOT JÚNIOR, AA. 2012. Estimativa da divergência genética em híbridos de milho destinados à formação de novas populações. Revista Agropecuária Catarinense 25: 80-83. 